Keywords

Latinos; HIV/AIDS; access to care; adherence; engagement in care

\title{
Introduction
}

Addressing barriers along the HIV care cascade for Latinos is key to achieving an AIDS free generation. ${ }^{1}$ In the US, there are 56.5 million Latinos/Hispanics who comprise $17.6 \%$ of the population. ${ }^{2}$ Yet HIV/AIDS has disproportionately affected Latino populations. Of the number of foreign-born persons diagnosed with HIV from 2007 to 2010 in the US, $42.2 \%$ were Latino, which is higher than the $34.4 \%$ who comprise foreign-born Latinos in the US.

Address correspondence to: Julie Levison, MD, MPhil, MPH, Division of General Internal Medicine, Massachusetts General Hospital, 100 Cambridge Street, Suite 1600, Boston, Massachusetts 02114, Phone: 617-724-4698, Fax: 617-726-2691, jlevison@ partners.org. Compliance with Ethical Standards:

- Conflicts of Interest: All authors have declared that no competing interests exist.

- $\quad$ Research involving human participants and/or animals: This article does not contain any studies with human participants or animals performed by any of the authors.

- Informed consent: No human participants participated in this study. 
2,3 Gay and bisexual men who have sex with men (MSM) represent $82.8 \%$ of new HIV infections in male Latinos. ${ }^{4}$ Place of birth is a crucial mediator of HIV risk, health care utilization, and health outcomes due to ease of accessing services for those with US residency. Educational level and health behaviors are also associated with country of origin; yet few studies disaggregate HIV outcomes for Latinos based on nativity. $3,5-8$

Once infected, Latinos experience disproportionately poorer clinical outcomes compared with non-Latino whites. This disparity represents a confluence of under-specified and unaddressed risk factors. The US Department of Health and Human Services recommends routine voluntary HIV testing for all adolescents and adults age 13-64 years. ${ }^{9}$ Despite this imperative, Latinos present with more advanced HIV disease at diagnosis. ${ }^{6,10,11}$ Furthermore, there is significant attrition from HIV care after diagnosis. ${ }^{12}$ An analysis of data from the National HIV Surveillance System and Medical Monitoring Project found that 83.9\% of HIV-infected Latinos were linked to care within 3 months of HIV diagnosis, compared with $87.1 \%$ in non-Latino whites. ${ }^{13}$ Nearly $60 \%$ of HIV-infected Latinos were retained in care, measured by $\geq 2 \mathrm{CD} 4$ or viral load tests performed at least 3 months apart in 2013. ${ }^{13}$ In 2009, the proportion of HIV-infected prescribed antiretroviral therapy (ART) was $89 \%$ in Latinos and $92 \%$ in non-Latino whites. ${ }^{14}$ By 2013 this disparity was no longer statistically significant. ${ }^{14}$ By 2013, $81 \%$ of Latinos and $86 \%$ of non-Latino whites achieved virologic suppression, a statistically significant disparity. ${ }^{14}$

Despite socioeconomic risk factors for poor health outcomes (i.e. high rates of poverty and low education), Latinos have good health profiles (e.g. life expectancy, birth weight, mortality from cancer). This is often described as the Latino health paradox. ${ }^{15,16}$ That HIV is one of the few conditions where outcomes in Latinos are worse than in non-Latino whites, as reflected in HIV incidence and death rates, reflects an important unaddressed health disparity. For example, in 2014, the rate of new HIV infections in Latinos was three times higher than in non-Latino whites, 18.4 cases per 100,000 persons compared with 6.1 for whites. ${ }^{17}$ When disaggregated by gender, the HIV incidence rate in Latino males was 3.2 times higher than in non-Latino white males and 3.8 times higher in Latina females compared with non-Latina white females. ${ }^{17}$ In 2014 , the death rate from HIV was 4.9 per 100,000 persons in Latinos compared with 2.5 in non-Latino whites. ${ }^{17}$ Evaluating risk factors that influence HIV outcomes in Latinos as well as community and individual assets could offer insight into overcoming these disparities.

Through a comprehensive literature search our intent is to identify key unaddressed components in the HIV care continuum that impinge upon adequate engagement in HIV care for Latinos. We review established models of HIV care utilization and identify factors relevant to Latino populations. We evaluate factors at the level of the patient, provider and clinic, and health system and society that are relevant to successful engagement for Latinos at each stage of HIV care (i.e. HIV diagnosis, linkage to HIV care, retention in HIV care, adherence to ART, and viral suppression). We use this platform to envision what is needed to improve HIV outcomes and halt HIV transmission through research and clinical care. 


\section{HIV Models of Care}

Traditionally, health services research measured HIV outcomes by "number of patients in primary care" or "quality of care", but these terms did not reflect longitudinal aspects in HIV care, such as retention in care, ART adherence, or viral suppression. ${ }^{18}$ In 2001, the Health Resources and Services Administration (HRSA) launched a five-year program to expand strategies to improve outreach to HIV-infected individuals out of care. ${ }^{19}$ These multi-site demonstration projects led to a more nuanced appreciation of the complex patterns of patient engagement in HIV care. In 2010, the National HIV/AIDS Strategy delineated specific indicators of effective HIV care: HIV diagnosis, linkage to care, retention in care, ART prescription and adherence, and viral suppression. ${ }^{20}$ The model of the HIV care continuum contains a series of bidirectional steps where HIV-infected individuals can transition between "not in care" to "fully engaged in care". 21

Mugavero and colleagues created a socioecological framework of HIV care utilization that is informed by concepts from the Andersen Model of Healthcare Utilization and the Information Motivation Behavioral Skills Model. ${ }^{22-24}$ In this model, factors that influence the process of engagement in HIV care fall under individual, interpersonal, community, health care system, and policy levels. The model emphasizes the concept of "churn", where individuals continuously cycle in and out of HIV care. ${ }^{25}$

Factors that relate to migration and acculturation influence health service utilization in Latinos and are relevant to highlight in HIV care. Nearly 35\% of US-based Latinos are foreign-born and a rising proportion of island-born Puerto Ricans have migrated to the US mainland. 2,26,27 The Behavioral Model for Vulnerable Populations builds upon the Andersen Model of Healthcare Utilization to examine access to care for minorities, including undocumented immigrants. ${ }^{28}$ Yang and Hang also offer an expanded conceptual model of the Andersen model of health service utilization accounting for both general and immigrant specific factors to explain disparities in health service utilization for immigrants compared with native-born persons. ${ }^{29}$ In this model, the macrostructural or contextual level includes the context of emigration and reception in the host country. Predisposing factors include immigration status and assimilation in the host society. Enabling factors center on financial and social resources from the homeland as well as transnational access to health care after migration. Immigrant specific health conditions and needs mediate the evaluated and perceived need for health care.

We emphasize factors specific to the stages of the HIV care continuum with the understanding that a number of factors are relevant across the care continuum at the level of the patient (e.g. acculturation, stigma around HIV and sexual orientation, self-efficacy); provider and clinic (e.g. quality of patient-provider relationship, cultural competency); and health system and society (e.g. access to health services, insurance status, laws and policy).

\section{Methods}

\section{Database and search strategy}

We used the following representative keywords and medical subject headings (MESH) terms to identify relevant articles to engagement in HIV care for Latinos: Latino, Hispanic, HIV/ 
AIDS, care cascade, care continuum, HIV conceptual models, Ryan White, insurance, Affordable Care Act, barriers to health care, barriers to HIV care, social and structural factors, geographic factors, disparities, non-English language proficiency, HIV testing, HIV diagnosis, HIV prevention, HIV risk behavior, antiretroviral adherence, retention in care, HIV outcomes, mortality, cultural factors, machismo, marianismo, fatalism, familism, health beliefs, self-efficacy, social support, patient activation, acculturation, stigma, HIV knowledge, HIV education, health state, health literacy, substance/drug use, injection drug use, men who have sex with men, young men who have sex with men, LGBT, sexual and gender identity, gender, country of origin, immigrant/foreign-born, migrant, behavioral interventions, financial incentives, community health workers, health communication, patient-provider communication, HIV provider characteristics, mobile device, digital device, digital health, smart phone, eHealth, mHealth, iHealth, social media, social network, shared decision making, clinical trial, randomized trial, observational, cohort, NA-ACCORD, CNICS, CDC, review, epidemiology, qualitative, and narrative.

We applied these search terms to electronic databases of PubMed, MEDLINE (Ovid), PsycINFO (Ovid), Google Scholar, and Harvard Discovery database for a broader range of sources. We limited the search to English or Spanish language publications from peerreviewed journals. References focused on primary research articles relating to Latinos/ Hispanics with HIV and were published after January 2010 to emphasize more recent research contributions. However, we included older seminal work particularly in areas that were understudied or were foundational references.

\section{HIV testing and diagnosis}

Patient-level factors-Lower HIV testing in Latinos varies by sub-ethnic group affiliation (i.e. Mexican and Mexican American groups), low educational level, male gender, and low self-perceived HIV risk. ${ }^{30,31}$ Lopez-Quintero also found that married Latinos displayed lower intentions for HIV testing, which may relate to traditional conceptions of gender and sexual identity and assumptions around marital fidelity. ${ }^{30}$

Cultural factors influence HIV testing in Latinos. Familismo (or family pride) can be associated with reluctance for Latinos to discuss sex and sexual identity. As well, strict cultural norms on sexuality and gender roles can limit the capacity and awareness for uptake of HIV testing. ${ }^{32-34}$ Social reluctance to discuss sexuality, prevention of sexually transmitted infections, sexual roles or attitudes in Latinas limits their ability to address HIV risks. ${ }^{35}$ Marianismo is a traditional female gender role in Latino culture that idealizes sexual purity and passivity. Women who subscribe to concepts of marianismo may not discuss safer sex with their male partners for fear of abuse, withdrawal of financial support, or fear of being perceived as promiscuous. This behavior may decrease willingness to undergo HIV testing in Latinas. ${ }^{36}$ In a survey of 413 predominantly Mexican American pregnant women in Texas, women were less likely to undergo HIV testing if they perceived testing as a reflection of sexual promiscuity or of injection drug use, endorsed a fatalistic perspective, and feared social consequences of a positive test result (e.g. withdrawal of financial support and affection). ${ }^{37}$ 
Social pressure for Latino men to conform to traditional gender roles can limit Latino males from prioritizing HIV testing for fear of the social repercussions of having the disease. ${ }^{38}$ Research around cultural sexual norms in Latino MSM relate self-perceived risk for HIV and perceived need for HIV testing. 39,40 More recent research examines Latino masculinity and sexual risk and extends prior understandings of Latino male willingness for HIV testing. $41-44$

Acculturation is the psychological and behavioral change that results from contact with another culture. ${ }^{45}$ Lopez-Quintero found that individuals with lower acculturation scores harbored lower intentions for HIV testing. ${ }^{30}$ Values such as respeto that encourage deference to authority figures, as well as low activation and English language skills, can limit Latino patients from requesting HIV testing when not offered by their provider. ${ }^{31,46}$ In a sample of 608 Latino MSM in Miami-Dade County and New York City, those most likely to avoid HIV testing did not disclose their sexual identity to their provider, which may reflect a confluence of cultural factors, such as not challenging authority figures, sensitivity around traditional gender roles, and language barriers. ${ }^{38}$

Provider and clinic-level factors-A significant predictor of the intention for HIV testing in Latinos is whether the health care provider offers the test. ${ }^{30,47}$ A CDC analysis of the 2009-2012 National Ambulatory Medical Care Survey of males aged 15-39, a high risk group for HIV, demonstrated that $1.0 \%$ of health care visits to physicians' offices included an HIV test. ${ }^{48}$ In a nationally representative sample of 17,848 Latinos, 50\% reported receiving an HIV test because it was part of a medical check-up or procedure. ${ }^{49}$ In a survey of 139 patients in New York City who were diagnosed with concurrent HIV and AIDS, or late testers, one-third were Latino. ${ }^{50}$ In the year prior to HIV diagnosis, $20 \%$ of these respondents reported a provider had offered HIV testing. ${ }^{50}$ In Houston, Texas, in a community health center serving a predominantly Latino population, $25.5 \%(n=27)$ of participants reported they were offered an HIV test at their first medical visit. ${ }^{51}$

While these studies show that provider offer of HIV testing is low, patient willingness to accept HIV testing is high when the test is offered. In a community sample of 255 Latino men in South Florida, mostly foreign-born MSM, 85.6\% were willing to accept an HIV test based on physician's recommendation. ${ }^{47}$ Reasons that clinical sites may not offer an HIV test include provider knowledge of HIV testing recommendations; insufficient time, staffing or space to provide counseling; and provider comfort-level..$^{52}$

Health system and societal-level factors-Clinical and non-clinical settings can offer HIV testing but inadequate access to health services in Latinos hampers uptake of HIV testing. ${ }^{53}$ Based on a study by the Pew Hispanic Center and the Robert Wood Johnson Foundation, $27 \%$ of Latinos do not have access to a usual source of health care ${ }^{54}$ Within Latinos, this finding is more common in immigrants, males, uninsured, those aged 18-29 compared with those aged $>29$ years, and those with lower education. ${ }^{54}$ The absence of a health provider visit in the past year increased the odds of not having undergone HIV testing (adjusted OR 1.78 [95\% CI 1.48-2.14]) in the 2000 National Health Interview Survey. ${ }^{30}$ 
Part of this barrier to health care for Latinos in part relates to health insurance coverage. With passage of the Patient Protection and Affordable Care Act (ACA), the national adult uninsured population decreased from $22.3 \%$ in 2010 to $13.0 \%$ in $2015 .{ }^{55}$ When disaggregated by race/ethnicity, Latinos remain the largest racial/ethnicity group uninsured at $17 \% .{ }^{56}$ Medicaid is a principal source of health insurance coverage for individuals with HIV. Medicaid coverage for routine HIV testing varies by state. Routine HIV testing is considered an optional benefit for adults older than age 21 and further limits access to HIV testing. 57

Geographic variation in HIV testing across the US overlaps with a shift in patterns of migration for Latinos. Labor opportunities in meat packing, construction, and service industries in the Southeast and Midwest regions promote Latino migration to these emerging destinations. These regions overlap with areas of less frequent HIV testing. ${ }^{58}$ Geographic variation in HIV testing could be explained by the lag in the expansion of health care services to meet the needs of the escalating number of Latinos moving to cities without established communities. ${ }^{59}$ Furthermore, Medicaid expansion varies by state. Most states absorbing this Latino migration have not adopted Medicaid expansion, limiting the availability of HIV testing. ${ }^{60}$

In addition to access to routine medical care, other venues such as substance use treatment facilities and correctional facilities can service as an important gateway for HIV testing. Barriers to substance use services for Latinos further impede access to HIV testing. ${ }^{61,62}$ Even if an individual establishes access to substance use services, HIV testing is not uniformly offered at all treatment facilities. ${ }^{63,64}$ Correctional facilities are an important portal for health care for incarcerated Latinos and the large migrant Latino population that traverse US detention facilities. Yet there is substantial variation in HIV testing practices in correctional facilities nationwide. ${ }^{65}$ In a nationally representative sample of 14,250 state prisoners and 3,686 federal prisoners, inmates were surveyed about their access to HIV testing. ${ }^{66}$ Latinos in the federal prisons had 50\% lower odds compared with non-Latino white prisoners for HIV testing during incarceration (AOR 0.48 ; $95 \% \mathrm{CI} 0.31-0.74$ ). Evidence from a large survey of incarcerated individuals in the North Carolina prison system (48\% were black and $52 \%$ were white or other), where $89.3 \%$ of prisoners wanted HIV testing at prison intake. ${ }^{67}$

A large proportion of new HIV infections in Latinos are in immigrants, yet guidelines for HIV testing in Immigration and Customs Enforcement (ICE) health care facilities recommend symptom-based rather than routine HIV screening. ${ }^{68}$ These guidelines depart from recommendations by the National Commission on Correctional Health Care and the CDC that support routine HIV testing. ${ }^{69,9}$

Criminalization of HIV and fear of deportation serve as important contextual factors relevant to uptake of HIV testing in Latinos. Up until 2010, HIV infection was reason to bar residence in the US; yet HIV infection remains associated with criminal behavior in many US states and reinforces associations between HIV diagnosis and fear of deportation in immigrants. ${ }^{70,71}$ Federal indecision about the status of undocumented immigrants raises 
challenges at the state level as to whether it is a good investment to effectively cover these types of preventative services. ${ }^{72}$

\section{Linkage to HIV care}

Patient-level factors-After a new HIV diagnosis, patients are vulnerable to delay linking to outpatient HIV care and treatment. The Attitudes and Beliefs and the Steps of HIV Care Study examined characteristics of individuals not linked to care in Houston, Texas, where $39 \%$ of the sample was Latino. ${ }^{73}$ Participants demonstrated high rates of comorbid depression, low self-efficacy, and active substance use. In another study of linkage to HIV care in hard-to-reach populations, 219 HIV-infected Latinos were interviewed regarding their barriers to HIV care. ${ }^{74}$ Primary Spanish language speakers were more likely than primary English speaking Latinos and non-Latinos to be concerned about stigma. Spanish speaking Latinos were concerned about disclosure of their HIV serostatus and sexual identity, upsetting their family or partner, and their healthcare provider inquiring about sexual practices and drug use. Furthermore, Spanish speaking Latinos were more likely to reflect fatalistic beliefs and lack of individual agency that diminished the urgency of HIV care. Other studies have corroborated additional psychological and informational barriers to linkage to care in Latinos such as feeling too sick to seek medical services, fear of burdening the family, denial of the importance of HIV, and lack of knowledge about the significance of delayed HIV care. ${ }^{75-77}$ Social support was also associated with earlier HIV diagnosis and linkage to care in the Houston-based cohort, though this finding needs to be validated in a larger Latino population. ${ }^{78}$

Provider and clinic-level-Strengths-based support through case management is an effective clinic-based intervention to link vulnerable patients to HIV care. ${ }^{79}$ Subgroup analysis of the Antiretroviral Treatment Access Study (ARTAS) demonstrated that a brief case management intervention focused on strengths-based support was significantly more effective in linking Latinos to HIV care than other ethnic groups. ${ }^{80}$ The authors noted that Latinos were recruited from HIV testing facilities that were more often co-located with HIV care services, which may have confounded the outcome of linkage to care.

The Adolescent Medicine Trials Network for HIV/AIDS Interventions clinic sites represents clinics (AMTUs) that care for adolescents, ages 12-24, in 13 cities in the US and Puerto Rico. Data from the AMTUs show that linkage to care among Latino youth was lower (70.9\%) than non-Latino whites (81.3\%). For all adolescents, linkage to care was higher in clinics that were "adolescent-only" rather than HIV specialty. ${ }^{77}$

These examples of effective linkage to care strategies highlight the importance of clinic characteristics and the health care worker providing linkage to HIV care, particularly where Latino cultural values underscore warmth and respect in interpersonal relations including in clinical encounters. ${ }^{81}$

Health system and societal-level factors-In a nationally representative sample of HIV-infected Latinos in the US, absence of a source for routine health care at the time of HIV diagnosis was associated with being male and HIV exposure from IDU and heterosexual sex. ${ }^{82}$ Furthermore, HIV-infected female Latinas, compared with male Latinos, 
were more likely to use the emergency room for routine health care. Based on the adolescent data from the AMTUs, linkage to care was improved when outreach workers received realtime data from the public health authorities to interact directly with HIV-infected youth. ${ }^{77}$ Building upon the value of personal contact, interventions that emphasize use of health system navigators, as well as frequent outreach attempts by health program staff, may be key system-level interventions to successfully link HIV-infected Latinos to HIV care, particularly for adolescent Latinos. ${ }^{83-85}$ Taken together, these data offer targets within the health care system that could facilitate improved linkage to HIV care for Latinos.

\section{Adherence to ART}

Patient-level factors-Adherence to ART in Latinos is affected by converging factors at the individual level that relate to socio-demographics (e.g. educational level, gender, age, financial security, homelessness, immigration status), cultural beliefs (e.g. beliefs about HIV, ART, and the role of medicine and religion), and psycho-social states (e.g. perceived stigma, mental health, self-efficacy, and perceived need for ART). In a sample of $81 \mathrm{HIV}$-infected monolingual Spanish-speaking patients, barriers to adherence were having low ART-related knowledge, low perceived need for ART, delayed refilling of prescriptions, and feeling overwhelmed. ${ }^{86}$ HIV-related stigma can lower ART adherence since internalized stigma can lead to difficulties in disclosing HIV status and concealment of the use of HIV medications. 87,88 Machismo was associated with decreased adherence to HIV medications in HIVinfected Latino males in Los Angeles. ${ }^{89}$ In this study, caballerismo, a construct of masculinity that encompasses a duty to protect, was associated with increased ART adherence. Further understanding of the relationship between gender roles on ART adherence may be an important lever to promote long-term adherence to ART for treatment as well as HIV prevention in Latinos. ${ }^{90}$

Simpler ART regimens, in the modern era of HIV treatment, alone may not obviate treatment interruptions in Latinos. For example, in a sample of 1,131 HIV-infected individuals recruited to participate in a survey on ART adherence, depressive symptoms strongly predicted 4-day ART interruptions in the past 3 months for Latinos (OR 1.80, p <0.05) compared with non-Latino whites. ${ }^{91}$ Furthermore, food insecurity is associated with ART adherence and certain classes of ART require food to maximize oral bioavailability. Non-adherence to ART was more common in Latino subgroups with higher rates of food insecurity, such as migrant farm workers. ${ }^{92}$

Patient activation is the confidence, skill, and knowledge an individual has that supports their active role in their health and health care. ${ }^{93}$ Patient activation has been associated with ART adherence. ${ }^{94}$ Latino immigrants have significantly lower patient activation scores than US-born Latinos. ${ }^{95,96}$ Given lower rates of patient activation in Latinos and particularly in Latino immigrants, this is likely an important target for optimizing ART adherence and HIV care engagement in Latino populations. ${ }^{97}$

Provider and clinic-level factors-Large cohorts, including the HIV Research Network, have not shown statistically significant differences in ART prescription in Latinos compared with non-Latino whites. ${ }^{98}$ However, perceived discrimination from the provider or 
lack of trust in the provider has been shown to limit ART adherence in Latinos. ${ }^{99,100}$ In the Steps in HIV Care Study, where 38\% of the cohort was Latino, trust in the provider was not associated with ART adherence. ${ }^{101}$ This finding reflects that trust in the provider can be critical in some, but not all, aspects of HIV care engagement.

Health system and societal-level-Insurance coverage is an important prerequisite to ART access. The Women's Interagency HIV Study showed that women having no insurance or private insurance were less likely than Medicaid enrollees to use ART, regardless of race/ ethnicity. ${ }^{102}$ The unadjusted odds ratio for non-use of ART was higher in Latina women than non-Latina white women. After controlling for insurance status and other population characteristics, the likelihood of ART non-use was no longer present in Latina women. This finding underscores the important role of expanding and improving insurance coverage to improve disparities in ART access for at least Latina women with HIV.

The AIDS Drug Assistance Program (ADAP) has been a critical source of access to medications and linkage to care for low-income HIV-infected individuals in the US. In 2015, $72 \%$ of ADAP recipients had viral suppression. ${ }^{103}$ While ADAP eligibility is independent of US residency status under the Affordable Care Act, financial eligibility criteria vary substantially by US state of residence, suggesting that access to medications for low-income HIV infected individuals is not uniform across the country. ${ }^{103,104}$ Furthermore, the fate of ADAP remains uncertain amidst the potential for national health reform.

In the past, ADAPs in many states used cost-containment strategies such as enrollment caps and waitlists. The use of waitlists on ADAPs peaked in September 2011 when 9,298 individuals eligible for ADAPs in 11 states were unable to access HIV prescription drugs. ${ }^{105}$ Future implementation of such cost-containment strategies could present a serious barrier to ART for low-income Latinos. ${ }^{106}$

\section{Retention in care}

Patient-level factors-Retention in care requires a series of consistent health-seeking behaviors and is therefore different from linkage to care. Latino males more so than Latina females showed greater non-retention in HIV care in Florida, and there was no difference in retention in US compared with foreign-born Latinos. ${ }^{107}$ Qualitative work with HIV-infected Latino immigrants and migrants and their HIV providers identified that HIV related stigma and homophobia in Latino communities were important factors related to retention in HIV primary care. ${ }^{108}$ Low English-language proficiency has been associated with higher stigmarelated concerns in HIV-infected Latinos. ${ }^{74}$ This finding underscores the importance of acculturation on HIV-associated attitudes and beliefs that influence use of HIV care. Additional patient-level factors associated with retention were social support, spirituality/ religiosity, and financial insecurity. HIV serostatus disclosure within the social network was another predictor of retention in care in HIV-infected Latino MSM as well as Latina females. 109

Low English language proficiency may also complicate Latino patient navigation of health insurance markets and the insurance application process. ${ }^{110} \mathrm{HIV}$-infected Latinos with low English language proficiency have described mistrust of interpreters, either due to concern 
of confidentiality or lack of fidelity of the interpretation. ${ }^{111}$ Qualitative work with Latinos shows that this mistrust in language interpretation erodes patients' confidence in the value of consistent attendance in HIV primary care. ${ }^{108}$

Provider and clinic-level factors-Quality of HIV care influences retention in care. For example, trust and rapport between patient and provider in the initial visits can predict downstream HIV-specific health behaviors, such as retention in care. ${ }^{112} \mathrm{~A}$ longitudinal qualitative study of HIV-infected individuals new to HIV care (23\% Latinos) reported factors, particularly important early in the HIV diagnosis, to facilitate retention in HIV care. Those factors were continuity of the provider to avoid repetition of sensitive information and provider empathy. ${ }^{112}$ In the Steps in HIV Care study, Latino patients exhibited the highest level of trust in physicians, compared with non-Hispanic blacks and whites. Physician trust significantly predicted retention in HIV care. ${ }^{101}$ In further qualitative work with Latino migrants and immigrants, a trusting relationship with the HIV provider provided a reliable source of clinical reminders for appointments, respected advice on the therapeutic benefit of staying in HIV care, and patient optimism for the future. ${ }^{108}$ All of these factors were particularly crucial during acute life stressors that could jeopardize HIV clinical attendance.

Lack of access to Spanish-speaking HIV providers may diminish the quality of HIV care. For example, monolingual Spanish-speaking Latinos with insurance often do not receive the same level of comprehensive, patient-centered care as do other individuals, due to language discordance between patient and provider. ${ }^{95}$ A 2011 survey found that health care providers felt that they could not give high-quality HIV care to Latinos as could providers of nonLatino Whites. ${ }^{113}$ Reasons for these disparities in treatment included time restrictions, patient's inability to pay, and communication difficulties. A study assessing physician and patient communication in HIV-infected patients found that provider interactions with Latino patients concentrated less on psychosocial content, yet Latino patients rated their encounters as higher quality than non-Latino white patients did. ${ }^{114}$

Clinic infrastructure factors influence the availability of HIV care and thus retention in care for Latinos. In a review of best practices in Ryan White HIV facilities, the following strategies were identified as important system-level strategies to overcome barriers to retention in HIV care in Latinos: integrated care (e.g. access to mental health and social services on-site); multi-disciplinary HIV clinical teams (e.g. obstetrics, dermatology, primary care, psychiatry) appointment reminders; flexible appointment scheduling (e.g. capacity for walk-ins or urgent visits); expanded clinic hours; consistent monitoring of laboratories, appointment attendance, and ART adherence to preempt disease progression and disengagement from care; discreet clinic name and location of clinic; universal screening for substance use and mental health to reduce stigma. ${ }^{115}$ These organizational characteristics emphasize the importance of welcoming facilities to sustain engagement with Latino HIV-infected patients where affordability, low-English language proficiency, concerns about stigma and privacy, and lack of familiarity with health system are common.

Health system and societal-level factors-As in linkage to care, health systems that use effective outreach workers have higher retention in care as was found in the AMTU cohort. ${ }^{77}$ Appropriate data sharing between public health authorities and clinics helps 
identify and engage out-of-care Latinos with HIV infection. For example, AMTU sites had higher retention in care when public health authorities provided outreach workers with patient-level data so the outreach workers could directly interact with HIV-infected youth.

Nonparticipation in HIV care and poor health consequences are likely when health systems are unwelcoming to undocumented immigrants or socio-political environments lead to concern for deportation in immigrants. ${ }^{116,117}$ For example, threats of deportation discourage Medicaid and Children's Health Insurance Program utilization participation even by legal immigrants and citizens as has been shown in mixed status families. ${ }^{118,119}$

\section{Viral suppression}

Patient-level virologic suppression is contingent upon adherence to ART. Community viral load, or the sum total of viral load in an HIV-infected population, also determines HIV transmission risk and new HIV infections. ${ }^{120}$ At the individual level, managing syndemics, 121 or co-occurring disorders such as mental health problems, substance use disorders, and prior trauma may be key to assure engagement across the HIV continuum and virologic suppression. ${ }^{122,123}$ Latino immigrants travel frequently for family and work commitments as well for medical care. This mobility can challenge continuity of HIV care and was associated with interruptions in ART adherence and poorer virologic outcomes in a large cohort of HIV-infected Latinos from the Dominican Republic. ${ }^{124,125}$ Mechanisms to support ART adherence during travel as well as training providers to adopt simpler and more tolerable treatment regimens will likely improve virologic outcomes and the quality of care.

At the health system level, coordination between medical, mental health, substance use treatment and correctional facilities are important predictors of viral suppression across populations and particularly in Latinos who have persistent barriers to these health services. $62,126,127$

When adjusting for race/ethnicity and other factors, access to private insurance compared with Medicaid without ADAP, and to ADAP for those uninsured, reduced the risk of unsuppressed viral load in the Women's Interagency HIV Study. ${ }^{128}$ Access to insurance and to ART through ADAP not only supports ART access, but also the ultimate clinical and public health goal of virologic suppression.

\section{Implications for the HIV research agenda}

Multi-level interventions that address barriers to HIV care at the level of the patient, clinic and provider, health system and community-level contexts are most likely to be effective in improving HIV outcomes for Latinos. ${ }^{129}$ There are successful examples of communitybased HIV prevention and testing interventions in Latino populations from areas of high HIV prevalence both in the US and in resource-limited countries. These efforts include home-based HIV testing, ${ }^{130-133}$ training Latino soccer players to serve as lay health advisors to promote sexual risk reduction, ${ }^{134}$ and HIV testing campaigns situated on internet social meet-up sites frequented by young Latino MSM. ${ }^{135-137}$ 
The quality of the patient-provider encounter remains an area for ongoing innovation to address Latino patients' concerns in HIV counseling and treatment. This means an acknowledgment of the possible mistrust and perceptions of discrimination that Latino patients feel in health care and social settings. Mechanisms to diversify the health care workforce as well as increase access to culturally and linguistically competent care from staff could create a more welcoming environment for Latino patients seeking HIV care. Shared decision-making emphasizes open communication between patients and providers, and is an understudied approach to evaluate the quality of Latino patient decision making around HIV prevention, testing, treatment and care services. Data from cancer treatment show the important role of family in clinical decision-making for Latino patients although this model needs further investigation in its application to clinical decision-making in HIV. 138

At the societal level, stigma around HIV, sexual orientation, and gender identity remains an overarching barrier to HIV service utilization in Latinos in the US. ${ }^{74,108,139}$ Mechanisms to help HIV-infected Latinos cope with stigma and build resiliency is one strategy as has been described in Latina female commercial sex workers. ${ }^{140}$ Durable stigma reduction at the community-level is ultimately key to changing norms around HIV-related behaviors. ${ }^{141,142}$.

Immigrants sustain social networks, practices, and relationships that bridge their countries of origin and settlement. ${ }^{143}$ Mechanisms to communicate and engage Latinos, regardless of their place of residence, will be important for consistent HIV appointment attendance as individuals move for work and family commitments. ${ }^{144}$ Potential interventions include mobile phone-based applications that do not require in-person contact. ${ }^{97}$ Binational interventions between the US and the consulate services (like the ventanillas de salud in the Mexican consulates) could improve coordination of HIV care as Latinos migrate across the border for economic opportunities. ${ }^{145}$ Latinos struggle with access to ART on both sides of the Mexico-US border, suggesting the need for cross-border efforts to coordinate these health services. ${ }^{146}$

HIV-infected Latinos represent a significant proportion of new HIV diagnoses and of those living with the disease. Patient-level, provider and clinic-based, and health system and social context level barriers account for reduced engagement in HIV care in US-based Latinos. These gaps in knowledge require further research and opportunities for intervention. Considering interventions at each of these levels will be critical to supporting improved HIV treatment and care outcomes.

\section{Acknowledgments}

Funding: The work was supported by the National Institutes Health (K23 MH100978, R01 DA034952), Harvard Catalyst/Harvard Clinical and Translational Science Center (National Center for Research Resources and the National Center for Advancing Translational Sciences, National Institutes of Health Award 8UL1TR000170-05), Harvard University Center for AIDS Research (P30-AI060354), and financial contributions from Harvard University and its affiliated academic health care centers. The funders had no role in study design, data collection and analysis, decision to publish, or preparation of the manuscript. The content is solely the responsibility of the authors and does not necessarily represent the official views of Harvard Catalyst, Harvard Medical School and its affiliated academic health care centers, or the National Institutes of Health.

The authors appreciate the efforts of Ms. Iman Kahn for editorial assistance in review of the manuscript. 


\section{References}

1. UNAIDS. [Accessed on April 23, 2018] Countries ready to fast track response to end the AIDS epidemic by 2030. Press Release September 25, 2014Available at http://www.unaids.org/en/ resources/presscentre/pressreleaseandstatementarchive/2014/september/20140925_pr_fast_track

2. Pew Research Center. [Accessed on April 23, 2018] Facts on US Latinos. 2016. Available at http:// www.pewhispanic.org/2017/09/18/facts-on-u-s-latinos-current-data/

3. Prosser AT, Tang T, Hall HI. HIV in persons born outside the United States, 2007-2010. JAMA. Aug 8; 2012 308(6):601-607. [PubMed: 22820630]

4. Gray KM, Valverde EE, Tang T, Siddiqi AE, Hall HI. Diagnoses and Prevalence of HIV Infection Among Hispanics or Latinos - United States, 2008-2013. MMWR Morb Mortal Wkly Rep. Oct 9; 2015 64(39):1097-1103. [PubMed: 26448539]

5. Sheehan DM, Trepka MJ, Dillon FR. Latinos in the United States on the HIV/AIDS care continuum by birth country/region: a systematic review of the literature. International journal of STD \& AIDS. Jan; 2015 26(1):1-12. [PubMed: 24810215]

6. Espinoza L, Hall HI, Hu X. Diagnoses of HIV infection among Hispanics/Latinos in 40 states and Puerto Rico, 2006-2009. J Acquir Immune Defic Syndr. Jun 1; 2012 60(2):205-213. [PubMed: 22334071]

7. Espinoza L, Hall HI, Selik RM, Hu XH. Characteristics of HIV infection among Hispanics, United States 2003-2006. Jaids. Sep; 2008 49(1):94-101. [PubMed: 18667927]

8. Chen NE, Gallant JE, Page KR. A systematic review of HIV/AIDS survival and delayed diagnosis among Hispanics in the United States. J Immigr Minor Health. Feb; 2011 14(1):65-81.

9. Division of HIV/AIDS Prevention, National Center for HIV/AIDS, Viral Hepatitis, STD, and TB Prevention. Centers for Disease Control. [Accessed on April 23, 2018] Revised Recommendations for HIV Testing of Adults, Adolescents, and Pregnant Women in Health-Care Settings. 2006. Available at: https://www.cdc.gov/mmwr/preview/mmwrhtml/rr5514a1.htm

10. Dennis AM, Wheeler JB, Valera E, et al. HIV risk behaviors and sociodemographic features of HIV-infected Latinos residing in a new Latino settlement area in the Southeastern United States. AIDS Care. 2013 Oct 01; 25(10):1298-1307. [PubMed: 23384328]

11. Trepka MJ, Fennie KP, Sheehan DM, Lutfi K, Maddox L, Lieb S. Late HIV diagnosis: Differences by rural/urban residence, Florida, 2007-2011. AIDS Patient Care STDS. Apr; 2014 28(4):188197. [PubMed: 24660767]

12. El-Sadr WM, Gamble TR, Cohen MS. Linkage from HIV testing to care: a positive test often leads nowhere. Sex Transm Dis. Jan; 2013 40(1):26-27. [PubMed: 23250299]

13. Centers for Disease Control and Prevention. Monitoring selected national HIV prevention and care objectives by using HIV surveillance data-United States and 6 dependent areas, 2014. HIV Surveillance Supplemental Report. 2016; 21(4) [Accessed April 23, 2018] Available at https:// www.cdc.gov/hiv/pdf/library/reports/surveillance/cdc-hiv-surveillance-supplemental-reportvol-21-4.pdf.

14. Beer L, Bradley H, Mattson CL, et al. Trends in Racial and Ethnic Disparities in Antiretroviral Therapy Prescription and Viral Suppression in the United States, 2009-2013. J Acquir Immune Defic Syndr. Dec 01; 2016 73(4):446-453. [PubMed: 27391389]

15. English PB, Kharrazi M, Guendelman S. Pregnancy outcomes and risk factors in Mexican Americans: the effect of language use and mother's birthplace. Ethnicity \& disease. Autumn;1997 7(3):229-240. [PubMed: 9467706]

16. Vaca FE, Anderson CL, Hayes-Bautista DE. The Latino adolescent male mortality peak revisited: attribution of homicide and motor vehicle crash death. Injury prevention: journal of the International Society for Child and Adolescent Injury Prevention. Apr; 2011 17(2):102-107. [PubMed: 21134905]

17. Centers for Disease Control and Prevention. HIV Surveillance Report. 2014; 26 [Accessed April 23, 2018] Available at: https://www.cdc.gov/hiv/pdf/library/reports/surveillance/cdc-hivsurveillance-report-us.pdf.

18. Eldred L, Malitz F. Introduction [to the supplemental issue on the HRSA SPNS Outreach Initiative]. AIDS, Patient Care, and STDs. 2007; 21:S1-2. 
19. HRSA Ryan White and Global HIV/AIDS Programs. [Accessed on April 23, 2018] SPNS Initiative: Targeted HIV outreach and intervention models for underserved HIV-positive populations not in care. 2001-2006. Available at: https://hab.hrsa.gov/about-ryan-white-hivaidsprogram/spns-outreach-underserved-populations

20. Division of HIV/AIDS Prevention, National Center for HIV/AIDS, Viral Hepatitis, STD, and TB Prevention, Centers for Disease Control and Prevention. [Accessed on April 23, 2018] Understanding the HIV Care Continuum. 2016. Available http://www.cdc.gov/hiv/pdf/library/ factsheets/cdc-hiv-care-continuum.pdf

21. Eldred L, Malitz F. Introduction. Aids Patient Care and Stds. Jun.2007 21:S1-S2.

22. Mugavero MJ, Norton WE, Saag MS. Health care system and policy factors influencing engagement in HIV medical care: piecing together the fragments of a fractured health care delivery system. Clin Infect Dis. Jan 15; 52(Suppl 2):S238-246.

23. Amico KR. A situated-Information Motivation Behavioral Skills Model of Care Initiation and Maintenance (sIMB-CIM): an IMB model based approach to understanding and intervening in engagement in care for chronic medical conditions. J Health Psychol. 2011; 16:1071-1081. [PubMed: 21459919]

24. Christopoulos KA, Das M, Colfax GN. Linkage and retention in HIV care among men who have sex with men in the United States. Clin Infect Dis. Jan 15; 2011 52( Suppl 2):S214-222. [PubMed: 21342910]

25. Mugavero MJ, Amico KR, Horn T, Thompson MA. The state of engagement in HIV care in the United States: from cascade to continuum to control. Clin Infect Dis. Oct; 2013 57(8):1164-1171. [PubMed: 23797289]

26. Cohn D, Patten E, Hugo Lopez M. Puerto Rican population declines on Island, Grows on US Mainland. Pew Research Center; Aug 11, 2014. Available at: http://www.pewhispanic.org/ 2014/08/11/puerto-rican-population-declines-on-island-grows-on-u-s-mainland/ [Accessed on April 23, 2018]

27. Alvarez L. New York Times. New York Times; U.S: Nov 17, 2017. A Great Migration From Puerto Rico Is Set to Transform Orlando. U.S. Section. Available at: https://www.nytimes.com/ 2017/11/17/us/puerto-ricans-orlando.html?_r=0 [Accessed on April 23, 2018]

28. Gelberg L, Andersen RM, Leake BD. The Behavioral Model for Vulnerable Populations: application to medical care use and outcomes for homeless people. Health Serv Res. Feb; 2000 34(6):1273-1302. [PubMed: 10654830]

29. Yang PQ, Hwang SH. Explaining immigrant health service utilization: A theoretical framework. SAGE Open. 2016 Apr-Jun;:1-15.

30. Lopez-Quintero C, Shtarkshall R, Neumark YD. Barriers to HIV-testing among Hispanics in the United States: analysis of the National Health Interview Survey, 2000. AIDS Patient Care STDS. Oct; 2005 19(10):672-683. [PubMed: 16232051]

31. Ma M, Malcolm LR. Cultural influences on HIV testing among Latino youth. Cult Health Sex. 2016; 18(4):470-480. [PubMed: 26430735]

32. Levy V, Page-Shafer K, Evans J, et al. HIV-related risk behavior among Hispanic immigrant men in a population-based household survey in low-income neighborhoods of northern California. Sex Transm Dis. Aug; 2005 32(8):487-490. [PubMed: 16041250]

33. Villarruel AM, Jemmott JB 3rd, Jemmott LS, Ronis DL. Predictors of sexual intercourse and condom use intentions among Spanish-dominant Latino youth: a test of the planned behavior theory. Nursing research. May-Jun;2004 53(3):172-181. [PubMed: 15167505]

34. Cianelli R, Villegas N, Lawson S, et al. Unique factors that place older Hispanic women at risk for HIV: intimate partner violence, machismo, and marianismo. J Assoc Nurses AIDS Care. Jul-Aug; 2013 24(4):341-354. [PubMed: 23790277]

35. Zambrana RE, Cornelius LJ, Boykin SS, Lopez DS. Latinas and HIV/AIDS risk factors: implications for harm reduction strategies. Am J Public Health. Jul; 2004 94(7):1152-1158. [PubMed: 15226136]

36. Villar-Loubet OM, Vamos S, Jones DL, Lopez E, Weiss SM. A cultural perspective on sexual health: HIV positive and negative monolingual Hispanic women in South Florida. Hispanic health 
care international: the official journal of the National Association of Hispanic Nurses. Jun 01; 2011 9(2):82-90. [PubMed: 24994949]

37. Parra EO, Doran TI, Ivy LM, Aranda JM, Hernandez C. Concerns of pregnant women about bing tested for HIV: a study in a predominately Mexican-American population. AIDS Patient Care STDS. Feb; 2001 15(2):83-93. [PubMed: 11224934]

38. Joseph HA, Belcher L, O’Donnell L, Fernandez MI, Spikes PS, Flores SA. HIV testing among sexually active Hispanic/Latino MSM in Miami-Dade County and New York City: opportunities for increasing acceptance and frequency of testing. Health Promot Pract. Nov; 2014 15(6):867880. [PubMed: 24920606]

39. Diaz RM, Ayala G. Love, passion and rebellion: Ideologies of HIV risk among Latino gay men in the USA. Culture, Health, and Sexuality. 1999; 1(3):277-293.

40. Jarama SL, Kennamer JD, Poppen PJ, Hendricks M, Bradford J. Psychosocial, behavioral, and cultural predictors of sexual risk for HIV infection among Latino men who have sex with men. AIDS Behav. Dec; 2005 9(4):513-523. [PubMed: 16328712]

41. Zeglin RJ. Assessing the role of masculinity in the transmission of HIV: a systematic review to inform HIV risk reduction counseling interventions for men who have sex with men. Arch Sex Behav. Oct; 2015 44(7):1979-1990. [PubMed: 25917411]

42. Fleming PJ, DiClemente RJ, Barrington C. Masculinity and HIV: Dimensions of Masculine Norms that Contribute to Men's HIV-Related Sexual Behaviors. AIDS Behav. Apr; 2016 20(4):788-798. [PubMed: 26696261]

43. Zea MC, Reisen CA, del Rio-Gonzalez AM, Bianchi FT, Ramirez-Valles J, Poppen PJ. HIV Prevalence and Awareness of Positive Serostatus Among Men Who Have Sex With Men and Transgender Women in Bogota, Colombia. Am J Public Health. Aug; 2015 105(8):1588-1595. [PubMed: 25602899]

44. Garcia LI, Lechuga J, Zea MC. Testing comprehensive models of disclosure of sexual orientation in HIV-positive Latino men who have sex with men (MSM). AIDS Care. 2012; 24(9):1087-1091. [PubMed: 22690708]

45. Berry JW. Acculturation and adaptation: health consequences of culture contact among circumpolar peoples. Arctic Med Res. Jul; 1990 49(3):142-150. [PubMed: 2206174]

46. Lescano CM, Brown LK, Raffaelli M, Lima LA. Cultural factors and family-based HIV prevention intervention for Latino youth. J Pediatr Psychol. Nov-Dec;2009 34(10):1041-1052. [PubMed: 19181820]

47. Fernandez MI, Bowen GS, Perrino T, et al. Promoting HIV testing among never-tested Hispanic men: a doctor's recommendation may suffice. AIDS Behav. Sep; 2003 7(3):253-262. [PubMed: 14586188]

48. Ham DC, Huang Y, Gvetadze R, Peters PJ, Hoover KW. Health Care Use and HIV Testing of Males Aged 15-39 Years in Physicians' Offices — United States, 2009-2012. MMWR Morb Mortal Wkly Rep. 2016; 65:619-622. [Accessed on April 23, 2018] Available at: DOI: 10.15585/ mmwr.mm6524a3 [PubMed: 27337096]

49. Murray K, Oraka E. Racial and ethnic disparities in future testing intentions for HIV: United States, 2007-2010: results from the National Health Interview Survey. AIDS Behav. Jul; 2014 18(7):1247-1255. [PubMed: 24136452]

50. Mills CW, Sabharwal CJ, Udeagu CC, et al. Barriers to HIV testing among HIV/AIDS concurrently diagnosed persons in New York City. Sex Transm Dis. Aug; 2011 38(8):715-721. [PubMed: 21844723]

51. Arya M, Patuwo B, Lalani N, et al. Are primary care providers offering HIV testing to patients in a predominantly Hispanic community health center? An exploratory study. AIDS Patient Care STDS. May; 2012 26(5):256-258. [PubMed: 22372868]

52. Johnson CV, Mimiaga MJ, Reisner SL, VanDerwarker R, Mayer KH. Barriers and facilitators to routine HIV testing: perceptions from Massachusetts Community Health Center personnel. AIDS Patient Care STDS. Nov; 2011 25(11):647-655. [PubMed: 22023315]

53. U.S. Centers for Disease Control and Prevention, Division of HIV/AIDS Prevention, Capacity Building Branch. [Accessed on May 18, 2018] Implementing HIV testing in nonclinical settings a 
guide for HIV testing providers. Mar 2, 2016. Available at: https://www.cdc.gov/hiv/pdf/testing/ cdc_hiv_implementing_hiv_testing_in_nonclinical_settings.pdf

54. Pew Research Center. [Accessed on April 23, 2018] Hispanics and health care in the United StatesAccess, information, and knowledge. Available at http://www.pewhispanic.org/2008/08/13/ hispanics-and-health-care-in-the-united-states-access-information-and-knowledge/

55. Cohen RA, Martinez ME. Health Insurance Coverage: Early Release of Estimates From the National Health Interview Survey, January-March 2015. Centers for Disease Control and Prevention; Aug, 2015

56. Zammitti EP, Cohen RA, Martinez ME. Health insurance coverage: Early release of estimates from the National Health Interview Survey, January - June 2016. National Center for Health Statistics; Nov, 2016. Available from: http://www.cdc.gov/nchs/nhis/releases.htm [Accessed on April 23, 2018]

57. Kaiser Family Foundation. [Accessed on April 23, 2018] State Medicaid Coverage of Routine HIV Screening. Feb 25, 2014. Available at http://kff.org/hivaids/fact-sheet/state-medicaid-coverage-ofroutine-hiv-screening/

58. Ohl ME, Perencevich E. Frequency of human immunodeficiency virus (HIV) testing in urban vs. rural areas of the United States: results from a nationally-representative sample. BMC Public Health. 2011; 11:681. [PubMed: 21884599]

59. Dolwick Grieb SM, Desir F, Flores-Miller A, Page K. Qualitative assessment of HIV prevention challenges and opportunities among Latino immigrant men in a new receiving city. J Immigr Minor Health. Feb; 2015 17(1):118-124. [PubMed: 24158380]

60. Kaiser Family Foundation. [Accessed on April 23, 2018] Current Status of Medicaid Expansion Decisions. Jul 7, 2016. Available at: http://kff.org/health-reform/slide/current-status-of-themedicaid-expansion-decision/

61. Guerrero EG, Marsh JC, Khachikian T, Amaro H, Vega WA. Disparities in Latino substance use, service use, and treatment: implications for culturally and evidence-based interventions under health care reform. Drug Alcohol Depend. Dec 15; 2013 133(3):805-813. [PubMed: 23953657]

62. Alegria M, Carson NJ, Goncalves M, Keefe K. Disparities in treatment for substance use disorders and co-occurring disorders for ethnic/racial minority youth. J Am Acad Child Adolesc Psychiatry. Jan; 2011 50(1):22-31. [PubMed: 21156267]

63. Pollack HA, D' Aunno T. HIV testing and counseling in the nation's outpatient substance abuse treatment system, 1995-2005. J Subst Abuse Treat. Jun; 2010 38(4):307-316. [PubMed: 20171038]

64. Guerrero EG, Cederbaum JA. Adoption and utilization of sexually transmitted infections testing in outpatient substance abuse treatment facilities serving high risk populations in the U.S. Int J Drug Policy. Jan; 2011 22(1):41-48. [PubMed: 20970314]

65. Maruschak LM, Berzofsky M, Unangst J. US Department of Justice and Bureau of Justic Statistics. Feb, 2015. Medical Problems of State and Federal Prisoners and Jail Inmates, 2011-12. Revised October 4, 2016

66. Dumont DM, Gjelsvik A, Chen N, Rich JD. Hispanics, incarceration, and TB/HIV screening: a missed opportunity for prevention. J Immigr Minor Health. Aug; 2013 15(4):711-717. [PubMed: 23292731]

67. Rosen DL, Golin CE, Grodensky CA, et al. Opt-out HIV testing in prison: informed and voluntary? AIDS Care. 2015; 27(5):545-554. [PubMed: 25506799]

68. US Immigration and Customs Enforcement. [Accessed April 23, 2018] ICE/DRO Detention Standard: Medical Care. Feb, 2013. Available at: http://www.ice.gov/doclib/dro/detentionstandards/doc/medical_care.doc

69. National Commission on Correctional Health Care. [Accessed April 23, 2018] Position Statement: Administrative management of HIV in correctional institutions. 2014. Available at: http:// www.ncchc.org/administrative-management-of-hiv-in-correctional-institutions

70. Lehman JS, Carr MH, Nichol AJ, et al. Prevalence and public health implications of state laws that criminalize potential HIV exposure in the United States. AIDS Behav. Jun; 2014 18(6):997-1006. [PubMed: 24633716] 
71. Massachusetts Department of Public Health, Bureau of Infectious Disease. [Accessed on April 23, 2018] United States Travel Ban Lifted for People Living with HIV. Feb, 2010. Available at http:// www.mass.gov/eohhs/docs/dph/aids/hiv-travel-ban-repeal.pdf

72. Fabi R, Saloner B. Covering Undocumented Immigrants — State Innovation in California. New England Journal of Medicine. 2016; 375:1913-1915. [PubMed: 27959599]

73. Bhatia R, Hartman C, Kallen MA, Graham J, Giordano TP. Persons newly diagnosed with HIV infection are at high risk for depression and poor linkage to care: results from the Steps Study. AIDS Behav. Aug; 2011 15(6):1161-1170. [PubMed: 20711651]

74. Rajabiun S, Rumptz MH, Felizzola J, et al. The impact of acculturation on Latinos' perceived barriers to HIV primary care. Ethn Dis. Autumn;2008 18(4):403-408. [PubMed: 19157242]

75. Mason HR, Marks G, Simoni JM, Ruiz MS, Richardson JL. Culturally sanctioned secrets? Latino men's nondisclosure of HIV infection to family, friends, and lovers. Health Psychol. Jan; 1995 14(1):6-12. [PubMed: 7737075]

76. Keesee MS, Natale AP, Curiel HF. HIV positive Hispanic/Latinos who delay HIV care: analysis of multilevel care engagement barriers. Soc Work Health Care. 2012; 51(5):457-478. [PubMed: 22583031]

77. Philbin MM, Tanner AE, DuVal A, et al. Factors affecting linkage to care and engagement in care for newly diagnosed HIV-positive adolescents within fifteen adolescent medicine clinics in the United States. AIDS Behav. Aug; 2014 18(8):1501-1510. [PubMed: 24682848]

78. Kelly JD, Hartman C, Graham J, Kallen MA, Giordano TP. Social support as a predictor of early diagnosis, linkage, retention, and adherence to HIV care: results from the steps study. J Assoc Nurses AIDS Care. Sep-Oct;2014 25(5):405-413. [PubMed: 24508174]

79. Gardner LI, Metsch LR, Anderson-Mahoney P, et al. Efficacy of a brief case management intervention to link recently diagnosed HIV-infected persons to care. AIDS. Mar 04; 2005 19(4): 423-431. [PubMed: 15750396]

80. Gardner LI, Marks G, Craw J, et al. Demographic, psychological, and behavioral modifiers of the Antiretroviral Treatment Access Study (ARTAS) intervention. AIDS Patient Care STDS. Sep; 2009 23(9):735-742. [PubMed: 19645619]

81. Flores G. Culture and the patient-physician relationship: achieving cultural competency in health care. J Pediatr. Jan; 2000 136(1):14-23. [PubMed: 10636968]

82. Morales LS, Cunningham WE, Galvan FH, Andersen RM, Nakazono TT, Shapiro MF. Sociodemographic differences in access to care among Hispanic patients who are HIV infected in the United States. Am J Public Health. Jul; 2004 94(7):1119-1121. [PubMed: 15226129]

83. Cabral HJ, Tobias C, Rajabiun S, et al. Outreach program contacts: do they increase the likelihood of engagement and retention in HIV primary care for hard-to-reach patients? AIDS Patient Care STDS. 2007; 21( Suppl 1):S59-67. [PubMed: 17563291]

84. Bradford JB, Coleman S, Cunningham W. HIV System Navigation: an emerging model to improve HIV care access. AIDS Patient Care STDS. 2007; 21( Suppl 1):S49-58. [PubMed: 17563290]

85. Koester KA, Morewitz M, Pearson C, et al. Patient navigation facilitates medical and social services engagement among HIV-infected individuals leaving jail and returning to the community. AIDS Patient Care STDS. Feb; 2014 28(2):82-90. [PubMed: 24517539]

86. Murphy DA, Roberts KJ, Hoffman D, Molina A, Lu MC. Barriers and successful strategies to antiretroviral adherence among HIV-infected monolingual Spanish-speaking patients. AIDS Care. Apr; 2003 15(2):217-230. [PubMed: 12856343]

87. Katz IT, Ryu AE, Onuegbu AG, et al. Impact of HIV-related stigma on treatment adherence: systematic review and meta-synthesis. Journal of the International AIDS Society. 2013; 16(3 Suppl 2):18640. [PubMed: 24242258]

88. Bogart LM, Wagner GJ, Galvan FH, Klein DJ. Longitudinal relationships between antiretroviral treatment adherence and discrimination due to HIV-serostatus, race, and sexual orientation among African-American men with HIV. Ann Behav Med. Oct; 2010 40(2):184-190. [PubMed: 20552416]

89. Galvan FH, Bogart LM, Wagner GJ, Klein DJ, Chen YT. Conceptualisations of masculinity and self-reported medication adherence among HIV-positive Latino men in Los Angeles, California, USA. Cult Health Sex. 2014; 16(6):697-709. [PubMed: 24730591] 
90. Galvan FH, Bogart LM, Wagner GJ, Klein DJ, Chen YT. Conceptualisations of masculinity and self-reported medication adherence among HIV-positive Latino men in Los Angeles, California, USA. Cult Health Sex. Jun; 2014 16(6):697-709. [PubMed: 24730591]

91. Sauceda JA, Johnson MO, Saberi P. Nonadherence as 4-day antiretroviral therapy interruptions: Do depression and race/ethnicity matter as much in the modern antiretroviral therapy era? AIDS Behav. Nov; 2016 20(11):2624-2628. [PubMed: 26767532]

92. Quandt SA, Arcury TA, Early J, Tapia J, Davis JD. Household food security among migrant and seasonal latino farmworkers in North Carolina. Public Health Rep. Nov-Dec;2004 119(6):568576. [PubMed: 15504448]

93. Cunningham PJ, Hibbard J, Gibbons CB. Raising low 'patient activation' rates among Hispanic immigrants may equal expanded coverage in reducing access disparities. Health Aff (Millwood). Oct; 2011 30(10):1888-1894. [PubMed: 21976331]

94. Marshall R, Beach MC, Saha S, et al. Patient activation and improved outcomes in HIV-infected patients. J Gen Intern Med. May; 2013 28(5):668-674. [PubMed: 23288378]

95. Ortega AN, Rodriguez HP, Vargas Bustamante A. Policy dilemmas in Latino health care and implementation of the Affordable Care Act. Annu Rev Public Health. Mar 18.2015 36:525-544. [PubMed: 25581154]

96. Alegria M, Sribney W, Perez D, Laderman M, Keefe K. The role of patient activation on patientprovider communication and quality of care for US and foreign born Latino patients. J Gen Intern Med. Nov; 2009 24( Suppl 3):534-541. [PubMed: 19842003]

97. Fiscella K, Boyd M, Brown J, et al. Activation of persons living with HIV for treatment, the great study. BMC Public Health. Oct 16.2015 15:1056. [PubMed: 26474979]

98. Fleishman JA, Yehia BR, Moore RD, Gebo KA, Agwu AL. Disparities in receipt of antiretroviral therapy among HIV-infected adults (2002-2008). Med Care. May; 2012 50(5):419-427. [PubMed: 22410406]

99. Moreno CL. The relationship between culture, gender, structural factors, abuse, trauma, and HIV/ AIDS for Latinas. Qual Health Res. Mar; 2007 17(3):340-352. [PubMed: 17301342]

100. Thrasher AD, Earp JA, Golin CE, Zimmer CR. Discrimination, distrust, and racial/ethnic disparities in antiretroviral therapy adherence among a national sample of HIV-infected patients. J Acquir Immune Defic Syndr. Sep 1; 2008 49(1):84-93. [PubMed: 18667919]

101. Graham JL, Shahani L, Grimes RM, Hartman C, Giordano TP. The Influence of Trust in Physicians and Trust in the Healthcare System on Linkage, Retention, and Adherence to HIV Care. AIDS Patient Care STDS. Dec; 2015 29(12):661-667. [PubMed: 26669793]

102. Lillie-Blanton M, Stone VE, Snow Jones A, et al. Association of race, substance abuse, and health insurance coverage with use of highly active antiretroviral therapy among HIV-infected women, 2005. Am J Public Health. Aug; 2010 100(8):1493-1499. [PubMed: 19910347]

103. National ADAP Monitoring Project: 2016 Annual Report. National Alliance of State and Territorial AIDS Directors (NASTAD); Feb, 2016. Available at https://www.nastad.org/sites/ default/files/2016-National-ADAP-Monitoring-Project-Annual-Report.pdf [Accessed on April 23, 2018]

104. Kaiser Family Foundation. [Accessed on April 23, 2018] ADAP Financial Eligibility as a Percent of the Federal Poverty Level. Available at: http://www.kff.org/hivaids/state-indicator/adapfinancial-eligibility-as-a-percent-of-the-federal-poverty-level/?currentTimeframe=0\&sortModel= \%7B\%22colId\%22:\%22Location\%22,\%22sort\%22:\%22asc\%22\%7D/

105. Kaiser Family Foundation. [Accessed on April 23, 2018] AIDS Drug Assistance Programs (ADAPs). Aug 16, 2017. Available at: https://www.kff.org/hivaids/fact-sheet/aids-drugassistance-programs/

106. Grossman CI, Purcell DW, Rotheram-Borus MJ, Veniegas R. Opportunities for HIV combination prevention to reduce racial and ethnic health disparities. Am Psychol. May-Jun;2013 68(4):237246. [PubMed: 23688091]

107. Sheehan DM, Fennie KP, Mauck DE, Maddox LM, Lieb S, Trepka MJ. Retention in HIV Care and Viral Suppression: Individual- and Neighborhood-Level Predictors of Racial/Ethnic Differences, Florida, 2015. AIDS Patient Care STDS. Apr; 2017 31(4):167-175. [PubMed: 28414260] 
108. Levison JH, Bogart LM, Khan IF, et al. 'Where it falls apart': Barriers to retention in HIV care in Latino immigrants and migrants. AIDS, Patient Care, and STDs. In press.

109. Wohl AR, Galvan FH, Myers HF, et al. Do social support, stress, disclosure and stigma influence retention in HIV care for Latino and African American men who have sex with men and women? AIDS Behav. Aug; 2011 15(6):1098-1110. [PubMed: 20963630]

110. Abreu M, Hynes HP. The Latino Health Insurance Program: a pilot intervention for enrolling Latino families in health insurance programs, East Boston, Massachusetts, 2006-2007. Prev Chronic Dis. Oct.2009 6(4):A129. [PubMed: 19755005]

111. Murphy DA, Johnston Roberts K, Hoffman D, Molina A, Lu MC. Barriers and successful strategies to antiretroviral adherence among HIV-infected monolingual Spanish-speaking patients. AIDS Care. 2003 Apr 01; 15(2):217-230. [PubMed: 12856343]

112. Dang BN, Westbrook RA, Hartman CM, Giordano TP. Retaining HIV Patients in Care: The Role of Initial Patient Care Experiences. AIDS Behav. Oct; 2016 20(10):2477-2487. [PubMed: 26910339]

113. Bustamante AV, Chen J. Physicians Cite Hurdles Ranging From Lack Of Coverage To Poor Communication In Providing High-Quality Care To Latinos. Health Aff. Oct; 2011 30(10):19211929.

114. Beach MC, Saha S, Korthuis PT, et al. Differences in patient-provider communication for Hispanic compared to non-Hispanic white patients in HIV care. J Gen Intern Med. Jul; 2010 25(7):682-687. [PubMed: 20238204]

115. Hargreaves M, Hidalgo J, Byrd V, Bagchi A, Kim J. Strategies for engaging and retaining Latinos in HIV Care. Vol. 2. Mathematic Policy Research, Inc; Aug, 2010 1-4.

116. Sommers BD, Parmet WE. Health care for immigrants--implications of Obama's executive action. N Engl J Med. Mar 26; 2015 372(13):1187-1189. [PubMed: 25806912]

117. Venkataramani AS, Tsai AC. Dreams Deferred - The Public Health Consequences of Rescinding DACA. N Engl J Med. Nov 2; 2017 377(18):1707-1709. [PubMed: 28902574]

118. Sommers BD, Tomasi MR, Swartz K, Epstein AM. Reasons for the wide variation in Medicaid participation rates among states hold lessons for coverage expansion in 2014. Health Aff (Millwood). May; 2012 31(5):909-919. [PubMed: 22566429]

119. Watson T. Inside the refrigerator: immigration enforcement and chilling effects in Medicaid participation. Cambridge, MA: National Bureau of Economic Research; Aug, 2010

120. Das M, Chu PL, Santos GM, et al. Decreases in community viral load are accompanied by reductions in new HIV infections in San Francisco. PLoS One. Jun 10.2010 5(6):e11068. [PubMed: 20548786]

121. Singer M, Bulled N, Ostrach B, Mendenhall E. Syndemics and the biosocial conception of health. Lancet. Mar 04; 2017 389(10072):941-950. [PubMed: 28271845]

122. Sullivan KA, Messer LC, Quinlivan EB. Substance abuse, violence, and HIV/AIDS (SAVA) syndemic effects on viral suppression among HIV positive women of color. AIDS Patient Care STDS. Jan; 2015 29( Suppl 1):S42-48. [PubMed: 25397666]

123. Espino SR, Fletcher J, Gonzalez M, Precht A, Xavier J, Matoff-Stepp S. Violence screening and viral load suppression among HIV-positive women of color. AIDS Patient Care STDS. Jan; 2015 29( Suppl 1):S36-41. [PubMed: 25561308]

124. Taylor BS, Reyes E, Levine EA, et al. Patterns of geographic mobility predict barriers to engagement in HIV care and antiretroviral treatment adherence. AIDS Patient Care STDS. Jun; 2014 28(6):284-295. [PubMed: 24839872]

125. Myers JE, Taylor BS, Rojas Fermin RA, et al. Transmitted drug resistance among antiretroviralnaive patients with established HIV type 1 infection in Santo Domingo, Dominican Republic and review of the Latin American and Caribbean literature. AIDS Res Hum Retroviruses. Jul; 2012 28(7):667-674. [PubMed: 21851324]

126. Calsyn RJ, Klinkenberg WD, Morse GA, Miller J, Cruthis R, OHTAH. Recruitment, engagement, and retention of people living with HIV and co-occurring mental health and substance use disorders. Aids Care-Psychol Socio-Med Asp Aids/Hiv. 2004; 16:S56-S70. 
127. Guerrero EG, Aarons GA, Grella CE, Garner BR, Cook B, Vega WA. Program Capacity to Eliminate Outcome Disparities in Addiction Health Services. Adm Policy Ment Health. Jan; 2016 43(1):23-35. [PubMed: 25450596]

128. Ludema C, Cole SR, Eron JJ Jr, et al. Impact of Health Insurance, ADAP, and Income on HIV Viral Suppression Among US Women in the Women's Interagency HIV Study, 2006-2009. J Acquir Immune Defic Syndr. Nov 1; 2016 73(3):307-312. [PubMed: 27763995]

129. US Department of Health and Human Services, Health Researcources and Services Administration, HIV/AIDS Bureau, Special Projects of National Significance. [Accessed on April 23, 2018] Introducing the Latino Initiative: Affirming Cultural Diversity through Culturally Competent Care. Aug 10, 2013. Available at: https://hab.hrsa.gov/sites/default/files/hab/About/ Parts/latinoinitiative.pdf

130. Sena AC, Hammer JP, Wilson K, Zeveloff A, Gamble J. Feasibility and acceptability of door-todoor rapid HIV testing among latino immigrants and their HIV risk factors in North Carolina. AIDS Patient Care STDS. Mar; 2010 24(3):165-173. [PubMed: 20214484]

131. Nunn A, Brinkley-Rubinstein L, Rose J, et al. Latent class analysis of acceptability and willingness to pay for self-HIV testing in a United States urban neighbourhood with high rates of HIV infection. J Int AIDS Soc. Jan 17; 2017 20(1):1-9.

132. Krakowiak D, Kinuthia J, Osoti AO, et al. Home-Based HIV Testing Among Pregnant Couples Increases Partner Testing and Identification of Serodiscordant Partnerships. J Acquir Immune Defic Syndr. Aug 1; 2016 72( Suppl 2):S167-173. [PubMed: 27355505]

133. Ware NC, Wyatt MA, Asiimwe S, et al. How home HIV testing and counselling with follow-up support achieves high testing coverage and linkage to treatment and prevention: a qualitative analysis from Uganda. J Int AIDS Soc. 2016; 19(1):20929. [PubMed: 27357495]

134. Rhodes SD, Hergenrather KC, Bloom FR, Leichliter JS, Montano J. Outcomes from a community-based, participatory lay health adviser HIV/STD prevention intervention for recently arrived immigrant Latino men in rural North Carolina. AIDS Educ Prev. Oct; 2009 21(5 Suppl): 103-108. [PubMed: 19824838]

135. Bauermeister JA, Pingel ES, Jadwin-Cakmak L, et al. Acceptability and preliminary efficacy of a tailored online HIV/STI testing intervention for young men who have sex with men: the Get Connected! program. AIDS Behav. Oct; 2015 19(10):1860-1874. [PubMed: 25638038]

136. Rhodes SD, McCoy TP, Tanner AE, et al. Using Social Media to Increase HIV Testing Among Gay and Bisexual Men, Other Men Who Have Sex With Men, and Transgender Persons: Outcomes From a Randomized Community Trial. Clin Infect Dis. Jun 01; 2016 62(11):1450 1453. [PubMed: 26980878]

137. Young SD, Cumberland WG, Nianogo R, Menacho LA, Galea JT, Coates T. The HOPE social media intervention for global HIV prevention in Peru: a cluster randomised controlled trial. The lancet. HIV. Jan; 2015 2(1):e27-32. [PubMed: 26236767]

138. Mead EL, Doorenbos AZ, Javid SH, et al. Shared decision-making for cancer care among racial and ethnic minorities: a systematic review. Am J Public Health. Dec; 2013 103(12):e15-29.

139. Earnshaw VA, Bogart LM, Dovidio JF, Williams DR. Stigma and racial/ethnic HIV disparities: moving toward resilience. Am Psychol. May-Jun;2013 68(4):225-236. [PubMed: 23688090]

140. Carrasco MA, Barrington C, Kennedy C, Perez M, Donastorg Y, Kerrigan D. 'We talk, we do not have shame': addressing stigma by reconstructing identity through enhancing social cohesion among female sex workers living with HIV in the Dominican Republic. Cult Health Sex. May; 2017 19(5):543-556. [PubMed: 27760507]

141. Derose KP, Bogart LM, Kanouse DE, et al. An intervention to reduce HIV-related stigma in partnership with African American and Latino churches. AIDS Educ Prev. Feb; 2014 26(1):2842. [PubMed: 24450276]

142. Frye V, Paige MQ, Gordon S, et al. Developing a community-level anti-HIV/AIDS stigma and homophobia intervention in new York city: The project CHHANGE model. Eval Program Plann. Aug.2017 63:45-53. [PubMed: 28371668]

143. Mouw T, Chavez S, Edelblute H, Verdery A. Bi-national Social Networks and Assimilation: A Test of the Importance of Transnationalism. Soc Probl. Aug 1; 2014 61(3):329-359. [PubMed: 25750462] 
144. Georgetti Gomez L, Hightow-Weidman L, Vergara-Rodriquez P, Wiersema J. Transnational Practices and Engagement in Care: Lessons from the SPNS Latino Access Initiative, 6332. 2016; National Ryan White Conference on HIV Care and Treatment; Available at: http://

latinoetac.ucsf.edu/sites/latinoetac.ucsf.edu/files/Transnationalism\%20and\%20Engagement $\% 20$ in\%20Care.pdf

145. Ventanillas de Salud. [Accessed on April 23, 2018] Available at: http://www.migrantclinician.org/ services/ventanillas-de-salud.html

146. Servin AE, Munoz FA, Zuniga ML. Healthcare provider perspectives on barriers to HIV-care access and utilisation among Latinos living with HIV in the US-Mexico border. Cult Health Sex. 2014; 16(5):587-599. [PubMed: 24592920] 